\title{
Cryptosporidium meleagridis and C. baileyi (Apicomplexa) in domestic and wild birds in Algeria
}

\author{
Abd Elkarim Laatamna ${ }^{1}$, Nikola Holubová ${ }^{2,3}$, Bohumil Sak ${ }^{2}$, Martin Kváć $\check{c}^{2,3}$ \\ ${ }^{1}$ Faculty of Natural Sciences and Life, University of Djelfa, Moudjbara, Djelfa, Algeria; \\ ${ }^{2}$ Institute of Parasitology, Biology Centre of the Czech Academy of Sciences, České Budějovice, Czech Republic; \\ ${ }^{3}$ Faculty of Agriculture, University of South Bohemia, České Budějovice, Czech Republic
}

\begin{abstract}
A total of 345 faecal samples were collected from domestic, captive and wild birds in rural areas, urban areas and a Zoo in Algeria. Samples were screened for the presence of parasites belonging to the genus Cryptosporidium Tyzzer, 1910 by microscopy and PCR analysis of the small-subunit rRNA (SSU), actin and 60-kDa glycoprotein (gp60) genes. Cryptosporidium spp. were detected in 31 samples. Sequence analysis of SSU and actin genes revealed the presence of C. baileyi Current, Upton et Haynes, 1986 in domestic chicken broilers $(n=12)$, captive ostriches $(n=4)$ and a wild mallard $(n=1)$, and C. meleagridis Slavin, 1955 in a graylag goose $(n=1)$, chickens $(n=11)$ and turkeys $(n=2)$. Twenty-three chicken and two turkey broilers from five farms were positive for cryptosporidia, with an overall prevalence of $2 \%$ and $6 \%$, respectively. Both C. meleagridis and C. baileyi were detected in farmed chicken broilers, with a prevalence ranging from $9 \%$ to $69 \%$. Farmed turkeys broilers were positive only for C. meleagridis, with a $13 \%$ prevalence at the animal level. Subtyping of $C$. meleagridis isolates at the gp60 locus showed the presence of subtype IIIgA22G3R1 in graylag goose and chicken broilers and IIIgA23G2R1 in chicken and turkey broilers. Infection with cryptosporidia was not associated with any clinical diseases. The results of the present study, which provides the first data on the prevalence of Cryptosporidium spp. in wild birds in Africa, demonstrate the presence of human pathogenic C. meleagridis in both domestic and wild birds in Algeria.
\end{abstract}

Keywords: avian cryptosporidia, PCR, epidemiology, Northern Africa

Birds are important to public and animal health because they carry various pathogens, including the zoonotic parasites of the genus Cryptosporidium Tyzzer, 1910 (see Reed et al. 2003, Graczyk et al. 2008). The genus Cryptosporidium comprises species of apicomplexan parasites that infect epithelial cells in the microvillus border of the gastrointestinal tract of all vertebrate classes (O’Donoghue 1995). Species of genus Cryptosporidium additionally infect the bursa of Fabricius, respiratory system and other organs in birds (Nakamura and Meireles 2015).

So far, only four bird specific species of Cryptosporidium have been described: Cryptosporidium meleagridis Slavin, 1955; Cryptosporidium baileyi Current, Upton et Haynes, 1986; Cryptosporidium galli Pavlásek, 1999; and Cryptosporidium avium Holubová, Sak, Horčičková, Hlásková, Květoňová, Menchaca, McEvoy et Kváč, 2016 (Slavin 1955, Current et al. 1986, Ryan et al. 2003a, Holubová et al. 2016). These species infect a broad spectrum of birds, although they differ in their host range and site of infection; C. meleagridis also causes disease in humans (McLauchlin et al. 2000, Cama et al. 2003). Besides these four species, 13 Cryptosporidium genotypes have been described in birds worldwide, including avian genotypes I-VI, black duck genotype, Eurasian woodcock genotype and goose genotypes I-V (Nakamura and Meireles 2015, Chelladurai et al. 2016).

Additionally, the major human pathogenic species C. hominis Morgan-Ryan, Fall, Ward, Hijjawi, Sulaiman, Fayer, Thompson, Olson, Lal et Xiao, 2002 and C. parvum Tyzzer, 1912 and the artiodactyl and rodent species $C$. andersoni Lindsay, Upton, Owens, Morgan, Mead et Blagburn, 2000 and C. muris Tyzzer, 1907 have been detected in birds (Graczyk et al. 1998, Zhou et al. 2004, Ng et al. 2006, Qi et al. 2014).

Although cryptosporidiosis is one of the most prevalent parasitic infections in domestic, captive and wild birds worldwide, research on cryptosporidia in birds has lagged well behind that in mammals (Kváč et al. 2014). A major gap in our understanding of the diversity of cryptosporidia in birds is lack of prevalence and, in particular, genotyping data from the African continent (Bezuidenhout et al. 1993, Penrith et al. 1994, Soltane et al. 2007, Berrilli et al. 2012, Baroudi et al. 2013). In the present study, we determined the occurrence of Cryptosporidium spp. in domesticated and wild birds in Algeria using molecular tools, including subtype identification of $C$. meleagridis. Additionally, the role of wild birds as natural source of cryptosporidia for farmed birds was evaluated. 


\section{MATERIALS AND METHODS}

\section{Samples}

A total of 345 faecal samples from juvenile and adult domestic and wild birds were collected at poultry farms, rural and urban areas, and a zoo at the Bourdj Bou Arreridj Setif and Algiers province of Algeria (Table 1). At poultry farms, chicken and turkey broilers were kept on soil and laying hens were kept in hatcheries/ cages. Birds from the zoo were housed in an aviary with a concrete floor or, in the case of ostriches, were kept on soil. Captive birds from urban areas were kept in bird cages. Faecal samples of wild and captive birds and poultry were obtained directly from the ground immediately after defecation. Cloacal contents of farmed birds were collected after necropsy. Each sample was placed into an individual sterile plastic container without fixative, transported to the laboratory in a cool box and stored at $4{ }^{\circ} \mathrm{C}$ until processing. All samples were screened for the presence of oocysts of cryptosporidia using the aniline-carbol-methyl violet staining method (Miláček and Vítovec 1985). Faecal consistency was noted at the time of sampling. The infection intensity was determined from the microscopic examination as number of oocysts per gram (OPG) according to Kváč et al. (2007).

\section{Molecular study}

DNA was extracted from $200 \mathrm{mg}$ of faeces by bead disruption for $60 \mathrm{~s}$ at $5.5 \mathrm{~m} / \mathrm{s}$ using $0.5 \mathrm{~mm}$ glass beads in a Fast Prep ${ }^{\circledR}$ 24 Instrument (MP Biomedicals, Santa Ana, CA, USA) followed by isolation/purification using a commercially available kit in accordance with the manufacturer's instructions (PSP Spin stool DNA Kit, STRATEC Molecular GmbH, Birkenfeld, Germany). Purified DNA was stored at $-20^{\circ} \mathrm{C}$ prior to being used for PCR analysis. A nested PCR approach was used to amplify a region of the small subunit of rRNA gene (SSU; $\sim 830 \mathrm{bp}$; Xiao et al. 1999, Jiang et al. 2005) and actin ( 1,066 bp; Sulaiman et al. 2002) in all samples. The $60 \mathrm{kDa}$ glycoprotein (gp60; $830 \mathrm{bp}$; Alves et al. 2003, Li et al. 2014, Guo et al. 2015) was amplified in positive samples on the basis of results of SSU and actin genotyping. Negative and positive controls (C. parvum) were included in all PCR sets. Purified secondary products (QIAquick ${ }^{\circledR}$ Gel Extraction Kit, Qiagen, Hilden, Germany) were sequenced in both directions with an ABI 3130 genetic analyser (Applied Biosystems, Foster City, CA, USA) using the secondary PCR primers.

The nucleotide sequences of each gene obtained in this study were edited using ChromasPro 1.7.5 software (Technelysium Pty Ltd., South Brisbane, Australia) and aligned with each other and with reference sequences from GenBank using MAFFT version 7 online server with automatic selection of alignment mode (http://mafft.cbrc.jp/alignment/software/). Phylogenetic analyses were performed and best DNA phylogeny models were selected using the MEGA6 software (Tamura et al. 2013). Phylogenetic trees with bootstrap support were inferred by maximum likelihood (ML) and maximum parsimony methods. The nucleotide sequences obtained in this study have been deposited in GenBank under accession numbers KY352474-KY352489.

\section{Statistical analyses}

A two-sample z-test for proportions (independent groups) was used to assess relationships between parasite detection (Crypto- sporidium spp.) and presence or absence of signs of diarrhoea. All computations were performed with R 2.15.1.

\section{RESULTS}

Microscopical examination revealed the presence of oocysts of cryptosporidia in 22 of 345 faecal samples, with an infection intensity ranging from 1,000-4,000 OPG. Targeting the SSU and actin genes, Cryptosporidium-specific DNA was detected in all microscopy-positive samples and in nine samples that were microscopy-negative (Table 1). The infection rate of cryptosporidia varied among regions and farms. The prevalence at commercial chicken and turkey farms reached up to $9-69 \%$ and $13 \%$, respectively (Table 1). Twelve examined animals suffered from diarrhoea at the time of sampling. However, only one of them was Cryptosporidium-positive (Table 1); thus, the presence of diarrhoea was not associated with Cryptosporidium infection $(p$ value $=0.1871)$

ML analysis of SSU and actin sequences revealed two distinct clusters among isolates of cryptosporidia from birds in the present study. Fourteen isolates clustered with $C$. meleagridis, sharing $100 \%$ sequence identity with C. meleagridis isolates with accession nos. AF112574 and AF382351. The remaining 17 isolates belonged to C. baileyi, sharing $100 \%$ sequence identity with accession nos. AF093495 and EU741853. Analysis of the gp60 gene of C. meleagridis isolates showed the presence of subtypes IIIgA22G3R1, in a wild goose $(\mathrm{n}=1)$ and chicken broilers $(\mathrm{n}=10)$, and IIIgA23G2R1 in turkey $(\mathrm{n}=2)$ and chicken broilers $(\mathrm{n}=1$; Table 1$)$. The gp60 gene of $C$. baileyi was not amplified by any of the used sets of primers. Cryptosporidium meleagridis and C. baileyi were found only on commercial farms and in wild birds. Cryptosporidia were not detected in traditionally bred poultry in rural areas.

\section{DISCUSSION}

In Algeria, only Baroudi et al. (2013) described the occurrence of Cryptosporidium meleagridis and C. baileyi in farmed poultry, whereas the occurrence of cryptosporidia in wild birds has not yet been studied. Therefore, the present study provides the first data on the prevalence of Cryptosporidium spp. in wild birds in Africa. Cryptosporidium baileyi is considered the most common avian species of Cryptosporidium worldwide and it has the broadest host range (Nakamura and Meireles 2015). In the present study, C. baileyi was detected in mallard, ostriches and chicken broilers. Whereas $C$. baileyi has been reported frequently in ducks and chickens worldwide (Morgan et al. 2001, Ryan et al. 2003b, Chvala et al. 2006, Huber et al. 2007), the only previous reports in ostriches have been from China and the Czech Republic (Ryan et al. 2003b, Wang et al. 2011). The overall prevalence of $C$. baileyi in ostriches in the present study reached $31 \%$, which is comparable to the data by Wang et al. (2011) who reported prevalence of $1-29 \%$, and lower than the $60 \%$ prevalence in farmed ostriches and rheas originating from Belgium, France, Netherlands, Portugal and Spain (Gordo et al. 2002). In contrast to the report of Wang et al. (2011), who did not detect 
Table 1. A survey of Cryptosporidium meleagridis Slavin, 1955 and C. baileyi Current, Upton et Haynes, 1986 in faecal samples of domestic, captive and wild birds based on microscopic and molecular examination.

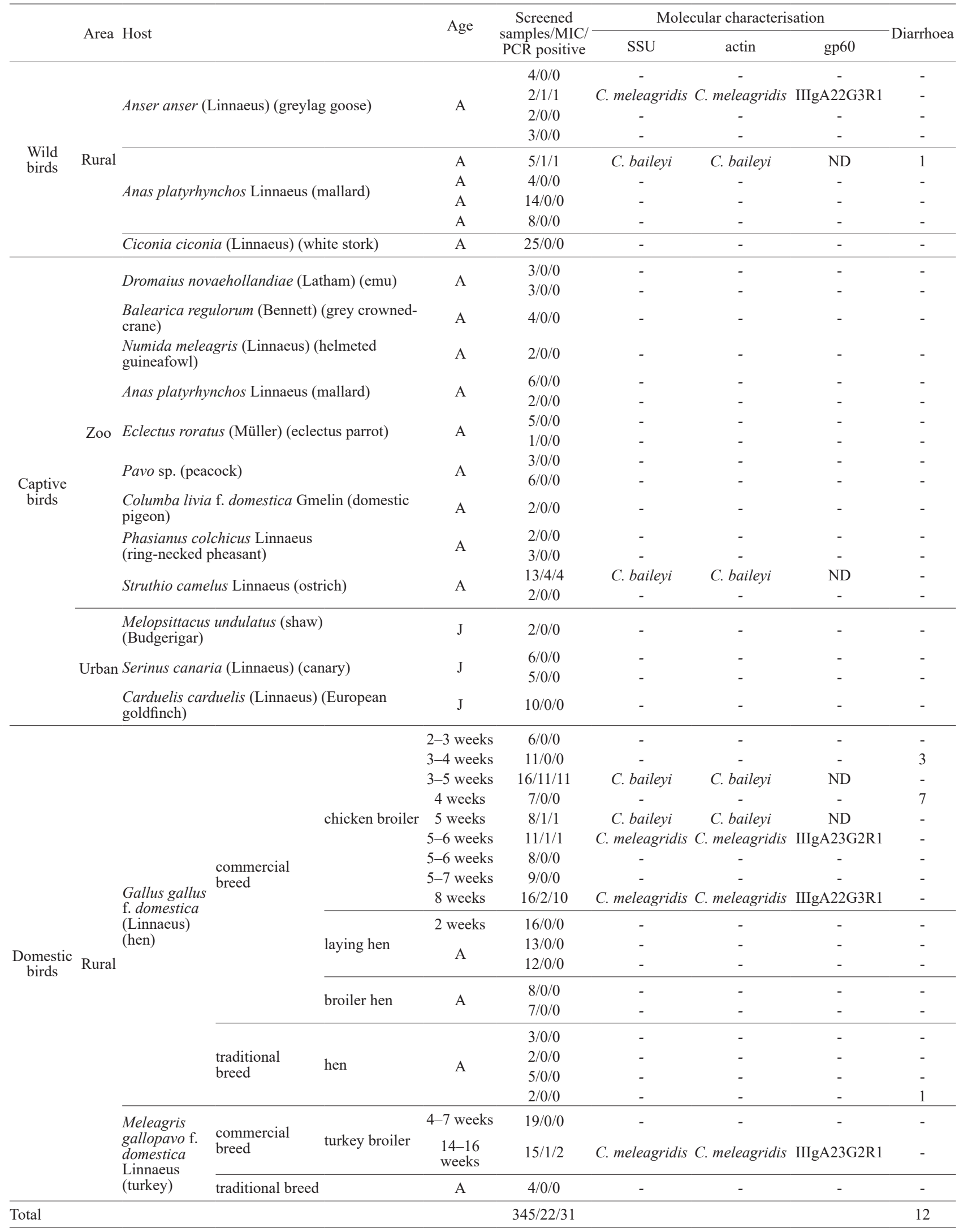

J - juvenile; A - adult; MIC - microscopy; PCR - Polymerase Chain Reaction; ND - not detected. 


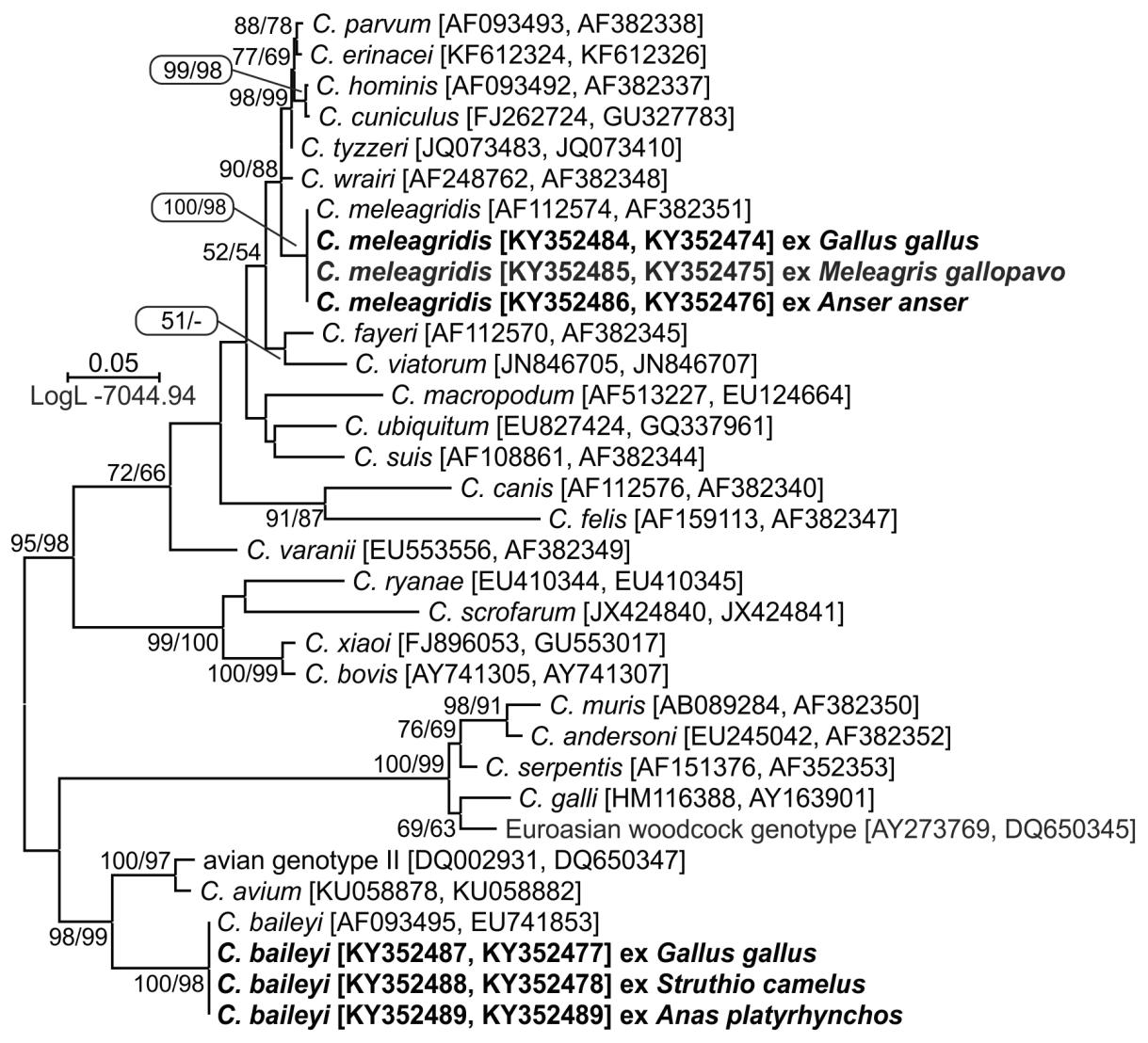

Fig. 1. Concatenated maximum likelihood tree (model Tamura 3-parameter G + I) based on partial small subunit ribosomal RNA and actin gene sequences of species and genotypes of Cryptosporidium Tyzzer, 1910, including those detected in the present study. Newly obtained sequences are bolded. Numbers at the nodes represent the bootstrap values (maximum likelihood/maximum parsimony; 1,000 replicates) gaining more than 50\% support. Branch length scale bar indicates number of substitution per site.

Cryptosporidium in ostriches older than 12 months of age, we reported a high prevalence in adult ostriches. Although there have been many reports concerning Cryptosporidi$u m$ infections in ostriches, the knowledge of species identity and their host and age specificity is far from clear. In contrast, the biological properties of $C$. baileyi in chicken is well known (Robertson et al. 2014). In Algeria, we detected a high prevalence of this species on a commercial farm, where $69 \%$ of screened birds were positive, and the overall prevalence of $C$. baileyi in this study varied from 9 to $69 \%$. Our findings are consistent with the reported prevalence of $C$. baileyi in flocks of chicken broilers in the USA (10-60\%) (Goodwin et al. 1996), Morocco (14-100\%) (Kichou et al. 1996) and China (7\%) (Wang et al. 2014).

Cryptosporidium meleagridis has been found at a high prevalence $(29 \%)$ in turkeys aged over 4 weeks in Algeria (Baroudi et al. 2013). In contrast, we detected the same species in only $13 \%$ of $14-16$ weeks old turkey broilers kept on the commercial farms, which is similar to the data reported by McEvoy and Giddings (2009), who found 3-11\% of 4-9 week-old poults infected with C. meleagridis. Similarly to turkey flocks, infection of chickens with C. meleagridis varied. In the present study, C. meleagridis was detected in $9-63 \%$ of chicken broilers. Wang et al. (2014) reported a much lower prevalence (less than $2 \%$ ) of C. meleagridis in chickens. In contrast, other authors reported C. meleagridis in 35-44\% of turkeys (Pavlásek
1994, Gharagozlou et al. 2006, Baroudi et al. 2013). These results show high variability among breeds worldwide, but different methodological approaches of surveys, differences in hygiene and host age likely play important role. In contrast to previous studies that frequently reported clinical cryptosporidiosis in turkeys and chickens (Goodwin 1988, Goodwin et al. 1988, Baroudi et al. 2013, Nakamura and Meireles 2015), infection with C. meleagridis was not associated with diarrhoea and mortality in the present study.

The importance of cryptosporidiosis in commercial poultry production has not yet been determined because few studies have examined the relationship between natural infection by Cryptosporidium spp. and production losses (Nakamura and Meireles 2015). The common occurrence of C. meleagridis, mainly in domestic birds, may have an impact on public health. Cryptosporidium meleagridis is the third most common human-pathogenic species in both developing and developed countries (Cama et al. 2008). All isolates of C. meleagridis detected in the present study belonged to family IIIg, which has been previously detected in birds and humans (Abal-Fabeiro et al. 2013, Baroudi et al. 2013, Stensvold et al. 2014). Two subtypes of C. meleagridis, IIIgA23G2R1 and IIIgA22G3R1, have not been reported previously from domestic chickens, turkeys and wild goose. The presence of subtype IIIgA22G3R1 in wild and farmed birds in this study suggests circulation 


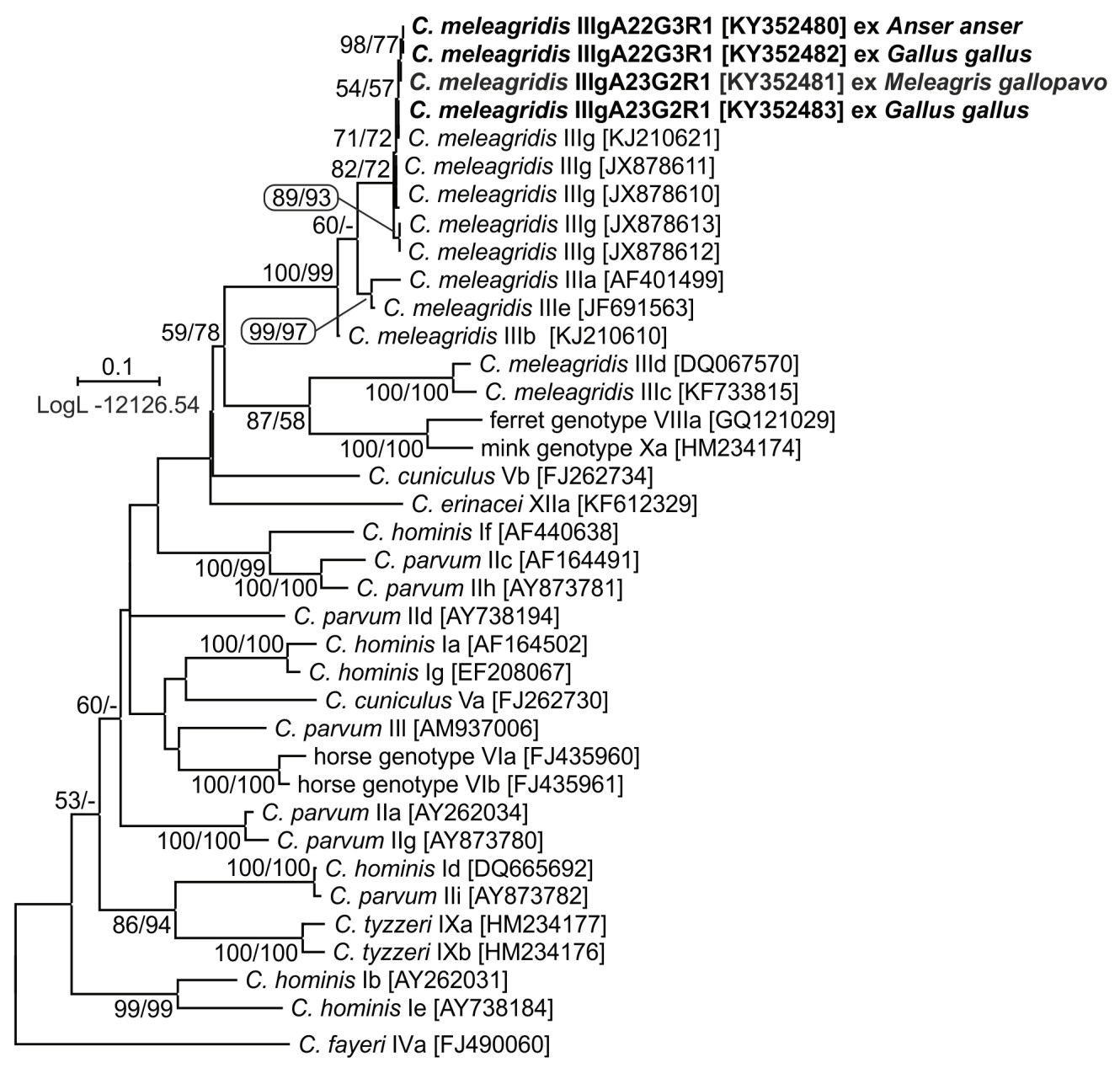

Fig. 2. Maximum likelihood tree (model General Time Reversible G + I) based on partial sequences of gp60 gene of species and genotypes of Cryptosporidium Tyzzer, 1910, including Cryptosporidium meleagridis Slavin, 1955 detected in the present study. Newly obtained sequences are bolded. Numbers at the nodes represent the bootstrap values (maximum likelihood/maximum parsimony; 1,000 replicates) gaining more than 50\% support. Branch length scale bar indicates number of substitution per site.

of parasites between wild and domestic animals. Due to the lack of gp60 subtyping on human cryptosporidiosis in North Africa, it is not known if the $C$. meleagridis subtypes reported in the present study are associated with human disease, although infections by this species has been previously reported in Tunisia (Essid et al. 2008, Rahmouni et al. 2014).
Acknowledgements. The authors thank the responsible veterinarians of Zoo of Ben Aknoun and Hamma, Samari Housam (private veterinarian in the province of Ras Eloued), Chebhi Yacine (private veterinarian in the province of Ras Eloued), Bettal Lotfi (private veterinarian in the province of Bousaada) for their help with material sampling. This study was funded by the Czech Science Foundation (project No. 15-01090S), Institute of Parasitology (RVO: 60077344) and the Grant Agency of the University of South Bohemia (project No. 082/2017/Z).

\section{REFERENCES}

Abal-Fabeiro J.L., Maside X., Bello X., Llovo J., BartoLOME C. 2013: Multilocus patterns of genetic variation across Cryptosporidium species suggest balancing selection at the gp60 locus. Mol. Ecol. 22: 4723-4732.

Alves M., Xiao L.H., Sulaiman I., Lal A.A., Matos O., AnTUNeS F. 2003: Subgenotype analysis of Cryptosporidium isolates from humans, cattle, and zoo ruminants in Portugal. J. Clin. Microbiol. 41: 2744-2747.

Baroudi D., Khelef D., Goucem R., Adjou K.T., Adamu H., Zhang H., XiaO L. 2013: Common occurrence of zoonotic pathogen Cryptosporidium meleagridis in broiler chickens and turkeys in Algeria. Vet. Parasitol. 196: 334-340.
Berrilli F., D’Alfonso R., Giangaspero A., Marangi M., Brandonisio O., Kabore Y., Gle C., Cianfanelli C., LaURO R., Di Cave D. 2012: Giardia duodenalis genotypes and Cryptosporidium species in humans and domestic animals in Cote d'Ivoire: occurrence and evidence for environmental contamination. Trans. R. Soc. Trop. Med. Hyg. 106: 191-195.

Bezuidenhout A.J., Penrith M.L., Burger W.P. 1993: Prolapse of the phallus and cloaca in the ostrich (Struthio camelus). J. S. Afr. Vet. Assoc. 64: 156-158.

Cama V.A., Bern C., Roberts J., Cabrera L., Sterling C.R., Ortega Y., Gilman R.H., Xiao L. 2008: Cryptosporidium species and subtypes and clinical manifestations in children, Peru. Emerg. Infect. Dis. 14: 1567-1574. 
Cama V.A., Bern C., Sulaiman I.M., Gilman R.H., Ticona E., Vivar A., Kawai V., Vargas D., Zhou L., Xiao L.H. 2003: Cryptosporidium species and genotypes in HIV-positive patients in Lima, Peru. J. Eukaryot. Microbiol. 50: 531-533.

Chelladurai J.J., Clark M.E., Kváč M., Holubová N., Khan E., Stenger B.L., Giddings C.W., McEvoy J. 2016: Cryptosporidium galli and novel Cryptosporidium avian genotype VI in North American red-winged blackbirds (Agelaius phoeniceus). Parasitol. Res. 115: 1901-1906.

Chvala S., Fragner K., Hackl R., Hess M., Weissenbock H. 2006: Cryptosporidium infection in domestic geese (Anser anser f. domestica) detected by in-situ hybridization. J. Comp. Pathol. 134: $211-218$

Current W.L., Upton S.J., Haynes T.B. 1986: The life cycle of Cryptosporidium baileyi n. sp. (Apicomplexa, Cryptosporidiidae) infecting chickens. J. Protozool. 33: 289-296.

Essid R., Mousli M., Aoun K., Abdelmalek R., Mellouli F., Kanoun F., Derouin F., Bouratbine A. 2008: Identification of Cryptosporidium species infecting humans in Tunisia. Am. J. Trop. Med. Hyg. 79: 702-705.

Gharagozlou M.J., Dezfoulian O., Rahbari S., Bokaie S., JAHANZAD I., RAZAVI A.N.E. 2006: Intestinal cryptosporidiosis in turkeys in Iran. J. Vet. Med. A 53: 282-285.

Goodwin M.A. 1988: Small-intestinal cryptosporidiosis in a chicken. Avian Dis. 32: 844-848.

Goodwin M.A., Brown J., Resurreccion R.S., Smith J.A. 1996: Respiratory coccidiosis (Cryptosporidium baileyi) among northern Georgia broilers in one company. Avian Dis. 40: 572 575.

Goodwin M.A., Steffens W.L., Russell I.D., Brown J. 1988 Diarrhea associated with intestinal cryptosporidiosis in turkeys. Avian Dis. 32: 63-67.

Gordo F.P., Herrera S., Castro A.T., Duran B.G., Diaz R.A.M. 2002: Parasites from farmed ostriches (Struthio camelus) and rheas (Rhea americana) in Europe. Vet. Parasitol. 107: 137-160.

Graczy T.K., Fayer R., Trout J.M., Lewis E.J., Farley C.A., Sulaiman I., Lal A.A. 1998: Giardia sp. cysts and infectious Cryptosporidium parvum oocysts in the feces of migratory Canada geese (Branta canadensis). Appl. Environ. Microbiol. 64: $2736-2738$.

Graczyk T.K., Majewska A.C., Schwab K.J. 2008: The role of birds in dissemination of human waterborne enteropathogens. Trends Parasitol. 24: 55-59.

Guo Y., Cebelinski E., Matusevich C., Alderisio K.A., Lebbad M., McEvoy J., Roellig D.M., Yang C., Feng Y., XiaO L. 2015: Subtyping novel zoonotic pathogen Cryptosporidium chipmunk genotype I. J. Clin. Microbiol. 53: 1648-1654.

Holubová N., SAK B., HorčIČKová M., Hlásková L., Květoñová D., Menchaca S., McEvoy J., Kváč M. 2016 Cryptosporidium avium n. sp. (Apicomplexa: Cryptosporidiidae) in birds. Parasitol. Res. 115: 2243-2251.

Huber F., da Silva S., Bomfim T.C., Teixeira K.R., Bello A.R. 2007: Genotypic characterization and phylogenetic analysis of Cryptosporidium sp. from domestic animals in Brazil. Vet. Parasitol. 150: 65-74.

Jiang J., Alderisio K.A., Xiao L. 2005: Distribution of Cryptosporidium genotypes in storm event water samples from three watersheds in New York. Appl. Environ. Microbiol. 71: 44464454

Kichou F., Saghir F., El Hamidi M. 1996: Infection naturelle à Cryptosporidium sp. chez le poulet de chair au Maroc. Avian. Pathol. 25: 103-111.

Kváč M., McEvoy J., Stenger B., Clark M. 2014: Cryptosporidiosis in other vertebrates. In: S.M. Cacciò and G. Widmer (Eds.), Cryptosporidium: Parasite and Disease. Springer, Wien, pp. 237-326.

KváČ M., OndráčKová Z., Květoñová D., SAK B., Vítovec J. 2007: Infectivity and pathogenicity of Cryptosporidium ander- soni to a novel host, southern multimammate mouse (Mastomys coucha). Vet. Parasitol. 143: 229-233.

Li N., Xiao L., Alderisio K., Elwin K., Cebelinski E., Chalmers R., Santin M., Fayer R., Kváč M., Ryan U., Sak B., Stanko M., Guo Y., Wang L., Zhang L., Cai J., Roellig D., Feng Y. 2014: Subtyping Cryptosporidium ubiquitum, a zoonotic pathogen emerging in humans. Emerg. Infect. Dis. 20: 217-224.

McEvoy J.M., Giddings C.W. 2009: Cryptosporidium in commercially produced turkeys on-farm and postslaughter. Lett. Appl. Microbiol. 48: 302-306.

Mclauchlin J., Amar C., Pedraza-Diaz S., Nichols G.L. 2000: Molecular epidemiological analysis of Cryptosporidium spp. in the United Kingdom: results of genotyping Cryptosporidium spp. in 1,705 fecal samples from humans and 105 fecal samples from livestock animals. J. Clin. Microbiol. 38: 3984-3990.

MiláčeK P., Vítovec J. 1985: Differential staining of cryptosporidia by aniline-carbol-methyl violet and tartrazine in smears from feces and scrapings of intestinal mucosa. Folia Parasitol. 32: 50 .

Morgan U.M., Monis P.T., Xiao L., Limor J., Sulaiman I., Raidal S., O’Donoghue P., Gasser R., Murray A., Fayer R., Blagburn B.L., Lal A.A., Thompson R.C. 2001: Molecular and phylogenetic characterisation of Cryptosporidium from birds. Int. J. Parasitol. 31: 289-296.

Nakamura A.A., Meireles M.V. 2015: Cryptosporidium infections in birds - a review. Rev. Bras. Parasitol. Vet. 24: 253-267.

Ng J., Pavlásek I., Ryan U. 2006: Identification of novel Cryptosporidium genotypes from avian hosts. Appl. Environ. Microbiol. 72: 7548-7553.

O'Donoghue P.J. 1995: Cryptosporidium and cryptosporidiosis in man and animals. Int. J. Parasitol. 25: 139-195.

PAVláseK I. 1994: [Localization of endogenous developmental stages of Cryptosporidium meleagridis Slavin, 1955 (Apicomplexa: Cryptosporidiidae) in birds]. Vet. Med. (Praha) 39: 733-742. (In Czech.)

Penrith M.L., Bezuidenhout A.J., Burger W.P., Putterill J.F. 1994: Evidence for cryptosporidial infection as a cause of prolapse of the phallus and cloaca in ostrich chicks (Struthio camelus). Onderstepoort J. Vet. 61: 283-289.

Qi M., Huang L., Wang R., Xiao L., Xu L., Li J., Zhang L. 2014: Natural infection of Cryptosporidium muris in ostriches (Struthio camelus). Vet. Parasitol. 205: 518-522.

Rahmouni I., Essid R., Aoun K., Bouratbine A. 2014: Glycoprotein 60 diversity in Cryptosporidium parvum causing human and cattle cryptosporidiosis in the rural region of Northern Tunisia. Am. J. Trop. Med. Hyg. 90: 346-350.

Reed K.D., Meece J.K., Henkel J.S., Shukla S.K. 2003: Birds, migration and emerging zoonoses: West Nile virus, Lyme disease, influenza A and enteropathogens. Clin. Med. Res. 1: 5-12.

Robertson L.J., BJörkMAN C., AxÉn C., FAYER R. 2014: Cryptosporidiosis in farmed Animals. In: S.M. Cacciò and G. Widmer (Eds.), Cryptosporidium: Parasite and Disease. Springer, Wien, pp. 149-236.

Ryan U., Xiao L., Read C., Zhou L., Lal A.A., Pavlásek I. 2003b: Identification of novel Cryptosporidium genotypes from the Czech Republic. Appl. Environ. Microbiol. 69: 4302-4307.

Ryan U.M., Xiao L., Read C., Sulaiman I.M., Monis P., Lal A.A., Fayer R., Pavlásek I. 2003a: A redescription of Cryptosporidium galli Pavlásek, 1999 (Apicomplexa: Cryptosporidiidae) from birds. J. Parasitol. 89: 809-813.

Slavin D. 1955: Cryptosporidium meleagridis (sp. nov.). J. Comp. Pathol. 65: 262-266.

Soltane R., Guyot K., Dei-Cas E., Ayadi A. 2007: Prevalence of Cryptosporidium spp. (Eucoccidiorida: Cryptosporiidae) in seven species of farm animals in Tunisia. Parasite 14: 335-338.

Stensvold C.R., Beser J., Axen C., Lebbad M. 2014: High applicability of a novel method for gp60-based subtyping of Cryptosporidium meleagridis. J. Clin. Microbiol. 52: 2311-2319. 
Sulaiman I.M., Lal A.A., Xiao L. 2002: Molecular phylogeny and evolutionary relationships of Cryptosporidium parasites at the actin locus. J. Parasitol. 88: 388-394.

Tamura K., Stecher G., Peterson D., Filipski A., Kumar S 2013: MEGA6: Molecular Evolutionary Genetics Analysis version 6.0. Mol. Biol. Evol. 30: 2725-2729.

Wang L., Xue X., Li J., Zhou Q., Yu Y., Du A. 2014: Cryptosporidiosis in broiler chickens in Zhejiang Province, China: molecular characterization of oocysts detected in fecal samples. Parasite 21: 36 .

Received 23 February 2017
Wang R.J., Qi M., Zhu J.J., Sun D., Ning C.S., ZhaO J.F., Zhang L.X., Xiao L.H. 2011: Prevalence of Cryptosporidium baileyi in ostriches (Struthio camelus) in Zhengzhou, China. Vet. Parasitol. 175: 151-154.

Xiao L., Escalante L., Yang C., Sulaiman I., Escalante A.A., Montali R.J., Fayer R., Lal A.A. 1999: Phylogenetic analysis of Cryptosporidium parasites based on the small-subunit rRNA gene locus. Appl. Environ. Microbiol. 65: 1578-1583.

Zhou L., Kassa H., Tischler M.L., Xiao L. 2004: Host-adapted Cryptosporidium spp. in Canada geese (Branta canadensis). Appl. Environ. Microbiol. 70: 4211-4215.

Published online 13 June 2017

Cite this article as: Laatamna A.E., Holubová N., Sak B., Kváč M. 2017: Cryptosporidium meleagridis and C. baileyi (Apicomplexa) in domestic and wild birds in Algeria. Folia Parasitol. 64: 018. 